\title{
Micostructure and Electrical Property of Semiconducting Tin Oxide Glaze
}

\author{
Masahiko NAKAMURA, Maruo KAMINO, Toshio NAGANO* \\ and Masafumi ARAKAWA \\ $\left(\begin{array}{l}\text { Department of Inorganic Materials, Faculty of Engineering and Design, Kyoto Institute of Technology } \\ \text { Matsugasaki, Sakyo-ku, Kyoto-shi, } 606 \\ \text { * Daito Co., Ltd. }\end{array}\right.$
}

半導性酸化スズ釉の微構造と電気的性質

中村雅彦・神野丸男・長野利雄 ${ }^{*} \cdot$ 荒川正文

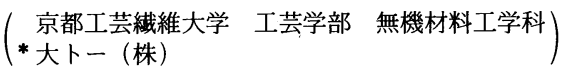

\begin{abstract}
The objective of present investigation was to understand the relationships between the microstructure and electrical properties of semiconducting $\mathrm{Sb}$ doped $\mathrm{SnO}_{2}$ glaze as a functional material. High electrical conduction is attributed to the three dimensional conduction network by highly conductive solution layers formed in the vicinity of undissolved semiconducting $\mathrm{SnO}_{2}$ particle surfaces. Crystalline $\mathrm{SnO}_{\mathbf{2}}$ particles smaller than $8 \mathrm{~nm}$ in diameter, responsible for high conductivity, were found in the solution layer with a high resolution TEM. A model experiment with the semiconducting $\mathrm{SnO}_{2}$-glass diffusion couple showed that the conductivity changed non-linearly with distance from the surface of an undissolved semiconducting $\mathrm{SnO} \mathrm{O}_{2}$ particle into the matrix region.

[Received February 9, 1987 ; Accepted April 21, 1987]
\end{abstract}

Key-words : Tin Oxide, Semiconducting glaze, Microstructure, Electrical property, Electro chemical corrosion

\section{Introduction}

The present objective material is a semiconducting glaze which is prepared by firing the mixture of base glaze powder and $\mathrm{SnO}_{2}$ particles doped with antimony oxide.

This glaze is started to be used for applications where the semiconductivity is required. One is for a semiconducting glaze insulator which can transmitt the electricity at extremely high voltage, thus limiting the radio frequency noise and also having superior electrical durability against flashover caused by the serious contaminations on the glaze surface. The other is for semiconducting floor and wall tiles for clean rooms.

This ceramic semiconducting tile is advantageous over existing organic ones in chemical and mechanical durabilities. Minor degradations such as surface roughening by pitting or linkings of small cracks are occur only after long term application under the loading condition of severely high voltage. These surface changes are apparently caused by electro-chemical and/or physical reactions between glaze surface and electrolyte contaminants.

The dominant mechanisms involved are ion exchange reactions between contaminants and glaze surface for the former case, and thermal
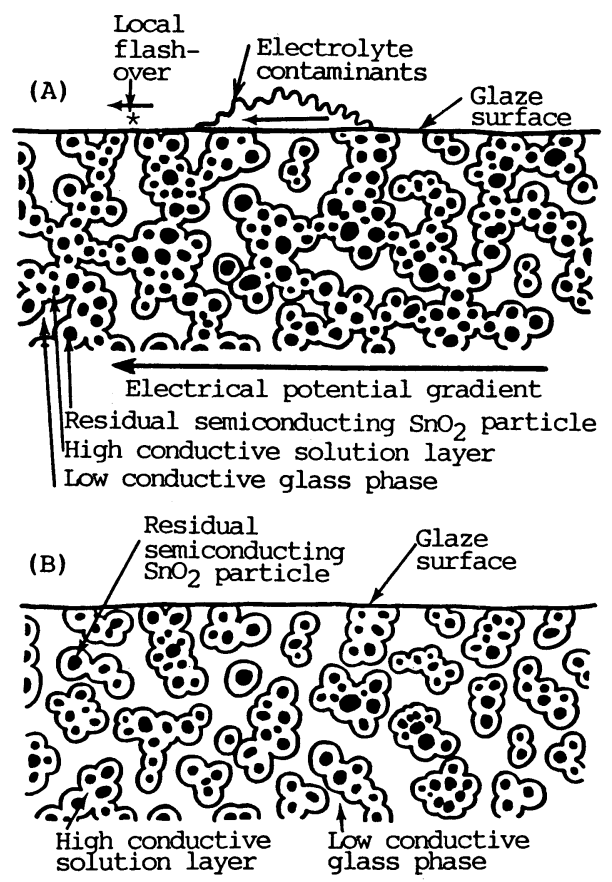

Fig. 1. Two dimensional schematical drawings for the electrical conduction in cross-section of (A) a high conductive glaze and (B) a less conductive one. 
cracking or pitting due to local discharge of small scale flashover for the latter case, respectively. Degradations of glaze are related closely to the microstructure, that is the formation of electrical conduction paths as shown in Fig. 1.

This paper is the extension of previous study ${ }^{1)}$ and more detailed research on microstructure and electrical conduction behavior is presented.

\section{Experimental procedures}

\section{1 Preparation of glaze samples}

Two kinds of sample were employed for (a) microstructural observation and (b) measurement of conductivity profile around semiconducting $\mathrm{SnO}_{2}$ particles in base glaze.

The procedures of sample preparation are respectively presented in Figs. 2 and 3. The commercial thin cover glass ( $160 \mu \mathrm{m}$ in thick) having almost the same chemical composition with that of base glaze for the sample (a) was applied for the sample (b).

\section{2 Measurement of conductivity}

Model specimen was electroded with gold and was placed between gold plates attached with coil springs as shown in Fig. 3. The glass surface was polished in parallel to the glass-crystal $\left(\mathrm{SnO}_{2}\right)$ interface and the electrical conductivity was intermittently measured after mechanical thinning.

The thickness of glass phase in the model

\begin{tabular}{|c|}
\hline \begin{tabular}{|l|} 
Firing a mixed powder (90wto $\mathrm{SnO}_{2}+$ \\
$\left.10 \mathrm{wt} \% \mathrm{Sb}_{2} \mathrm{O}_{5}\right)$ at $1500^{\circ} \mathrm{C}$ for $3 \mathrm{hrs}$ in \\
a non-lidded $\mathrm{Al}_{2} \mathrm{O}_{3}$ crucible
\end{tabular} \\
\hline$\downarrow$ \\
\hline $\begin{array}{l}\text { Preparation of semiconducting glaze } \\
\text { by firing mixed batch (50wt\% } \sim 1 \mathrm{wt} \% \\
\text { semiconducting } \mathrm{SnO}_{2}+50 \mathrm{wt} \% \text { } \sim 99 \mathrm{wt} \% \\
\text { base glaze) at } 1300^{\circ} \mathrm{C} \text { for } 3 \mathrm{hrs} \text { in } \\
\text { a non-lidded } \mathrm{Al}_{2} \mathrm{O}_{3} \text { crucible }\end{array}$ \\
\hline 1 \\
\hline $\begin{array}{l}\text { Mechanical thinning to } 10 \mathrm{~nm} \text { thick } \\
\text { of thin glaze section cut from the } \\
\text { massive glaze ingot by } 0.25 \mu \mathrm{m} \text { dia- } \\
\text { mond powder }\end{array}$ \\
\hline$\downarrow$ \\
\hline $\begin{array}{l}\text { Ion- or chemical (HF)- thinning to } \\
\text { 10nm thick of mechanically thinned } \\
\text { section }\end{array}$ \\
\hline$\downarrow$ \\
\hline $\begin{array}{l}\text { Setting thin section on Au micro- } \\
\text { grid supported with carbon deposi- } \\
\text { tion film (type of electron micro- } \\
\text { scope used: H-800 HITACHI Co.,Ltd.) }\end{array}$ \\
\hline
\end{tabular}

Fig. 2. Flow sheet for the preparation of a thin sample for TEM observation of the microstructure around a semiconducting $\mathrm{SnO}_{2}$ particle in a glaze.

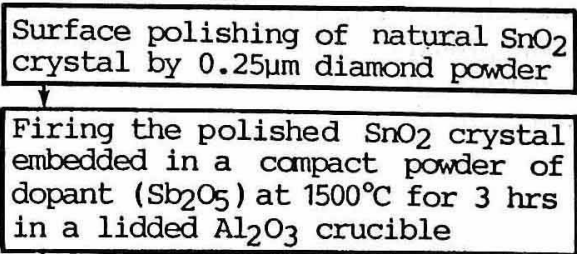

in a lidded $\mathrm{Al}_{2} \mathrm{O}_{3}$ crucible

Repolishing of the semiconducting
$\mathrm{SnO}_{2}$ surface by $0.25 \mu \mathrm{m}$ diamond
powder

Setting a thin glass plate on the polished flat surface of semioonducting $\mathrm{SnO}_{2}$.crystal and firing at $1300^{\circ} \mathrm{C}$ for 3 hrs

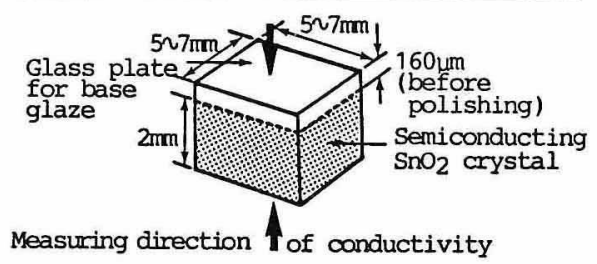

Fig. 3. Flow sheet for the preparation of a model sample for the measurement of electrical conductivity in the solution layer around a semiconducting $\mathrm{SnO}_{2}$ particle surface.

specimen was given by the mean determined with two methods, i.e. SEM observation and the measurement of weight (the balance accurate to $0.001 \mathrm{mg}$, LM-20 Shimadzu Co., Ltd. ).

A digital multimeter (TR-6840 Takedariken Co., Ltd. ) was employed for measurement of electrical conductivity under $\mathrm{DC} 2 \mathrm{~V}$ loading.

\section{Results and discussion}

\section{1 Microstructural observation}

Figure 4 shows the bright field TEM image of $50 \mathrm{wt} \% \mathrm{SnO}_{2}$ glaze sample. Two types of particle having different sizes are found. One is rounded large particle of a single or twined crystal having

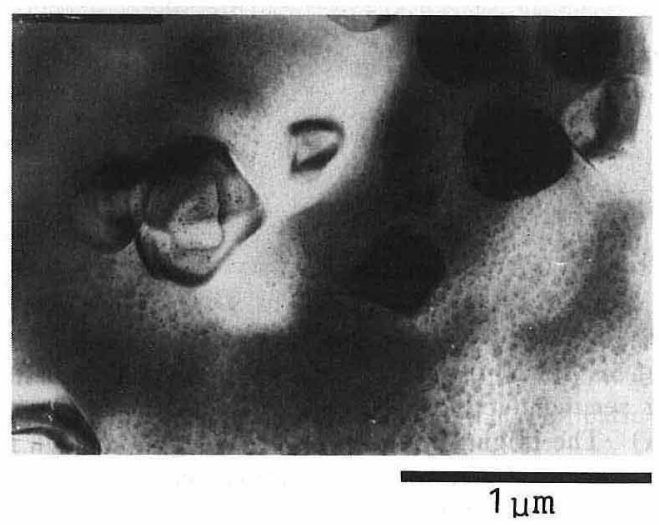

Fig. 4. Bright field TEM image of the semiconducting glaze $\left(50 \mathrm{wt} \% \mathrm{SnO}_{2}\right)$ under low magnification. 
the size about $0.3-0.5 \mu \mathrm{m}$ in diameter. It represents the primary particle of the secondary aggregate particle in starting semiconducting $\mathrm{SnO}_{2}$ powder (about $3 \mu \mathrm{m}$ mean diameter). During firing, aggregate particles are partially dispersed into base glaze and disintegrated into several numbers of rounded primary particle. Another type of particle in Fig. 4 is quite small in size and is dotted like a cloud filling up the matrix region.

A TEM examination at much higher magnification shows that these dotted small particles are spherical (diameter below about $8 \mathrm{~nm}$ ) as presented in Fig. $5(\mathrm{~A})$. The electron diffraction of Fig. 5 (A) represents the crystal lattice planes of

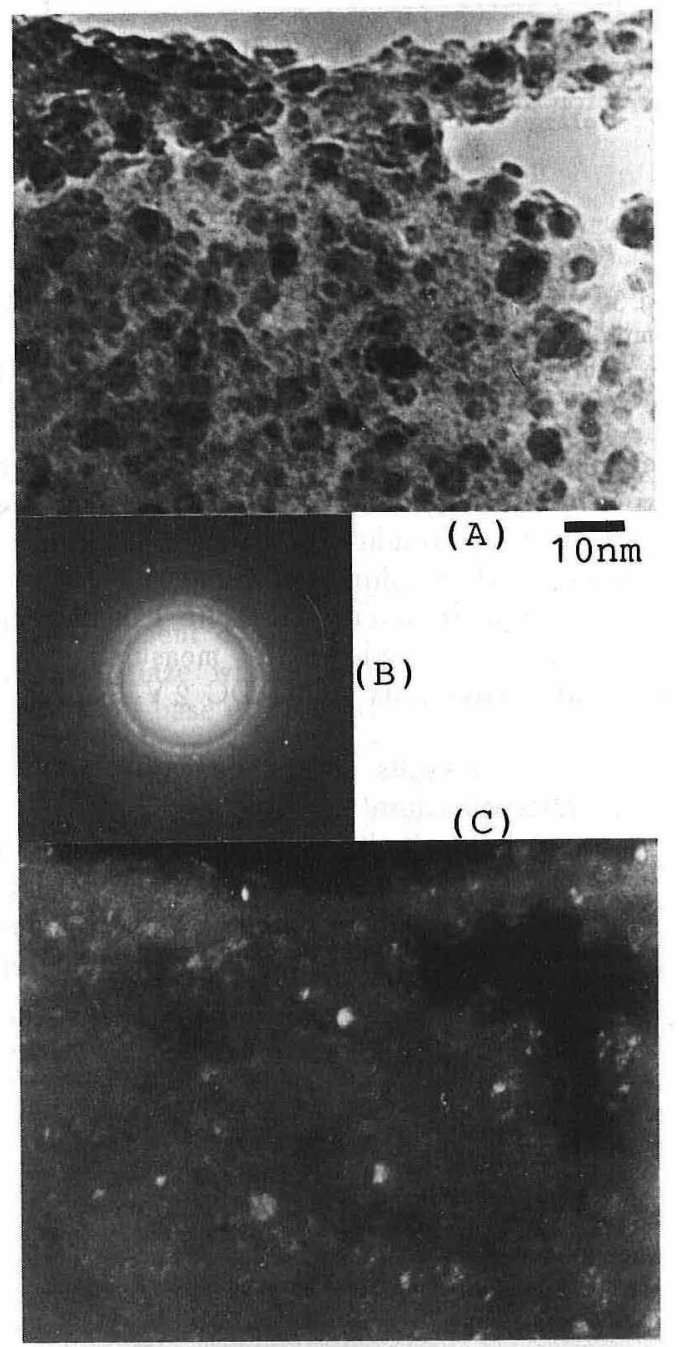

Fig. 5. TEM images observed at high magnification for semiconducting glaze ( $50 \mathrm{wt} \% \mathrm{SnO}_{2}$ ).

(A) The bright field image for the region of high tin concentration in the solution layer,

(B) The electron diffraction pattern for the same region as (A),

(C) The dark field image for the same region as (A)
$\mathrm{SnO}_{2}$ as shown in Fig. 5 (B). Moreover, several white particles in dark field image of Fig. 5 (A) satisfy the Bragg's diffraction condition as shown in Fig. $5(\mathrm{C})$.

These two experimental evidences show that these small spherical particles are of crystalline $\mathrm{SnO}_{2}$. The spherical shape and the steric configuration of these fine particles can be seen more clearly in the SEM image (Fig. 6) taken on the same sample of Fig. $5(\mathrm{~A})$. Further, the high conductive solution layers around undissolved $\mathrm{SnO}_{2}$ particles (diameter of $0.3-0.5 \mu \mathrm{m}$ ) were constituted of great number of these small crystalline $\mathrm{SnO}_{2}$ particles.

SEM observation confirms the model proposed for the formation of electrical conduction path in Fig. 1. Figure 7 shows the charging-up image of the same sample used in Fig. 4 but without a conductive coating. The dark gray area corresponds to the low potential region of high conductive solution layer. The white area shows the region of high potential, where electron charging-up occurs due to the region of less conductive base glaze. The contrast contour in Fig. 7 agrees

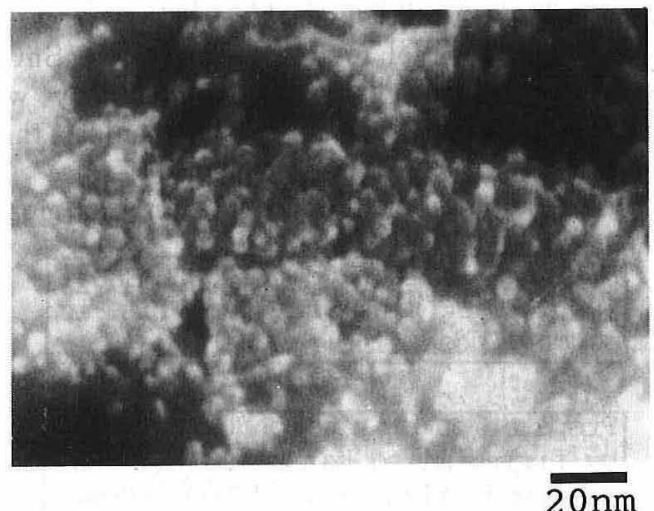

Fig.6. SEM image of the semiconducting glaze (50 wt \% $\mathrm{SnO}_{2}$ ).

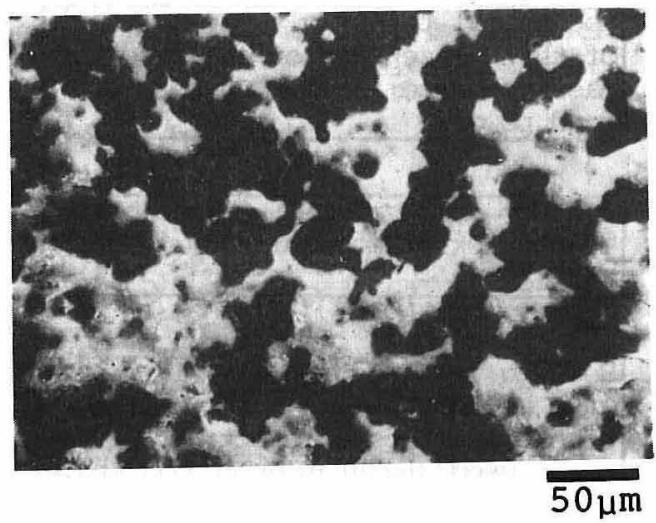

Fig. 7. SEM image showing electrical chargıng-up of the semiconducting glaze (50 wt $\% \quad \mathrm{SnO}_{2}$ ). 
well with the schematical microstructural image (Fig. 1) proposed for the formation of electrical conduction path in the glaze.

Small spherical crystalline $\mathrm{SnO}_{2}$ particles are

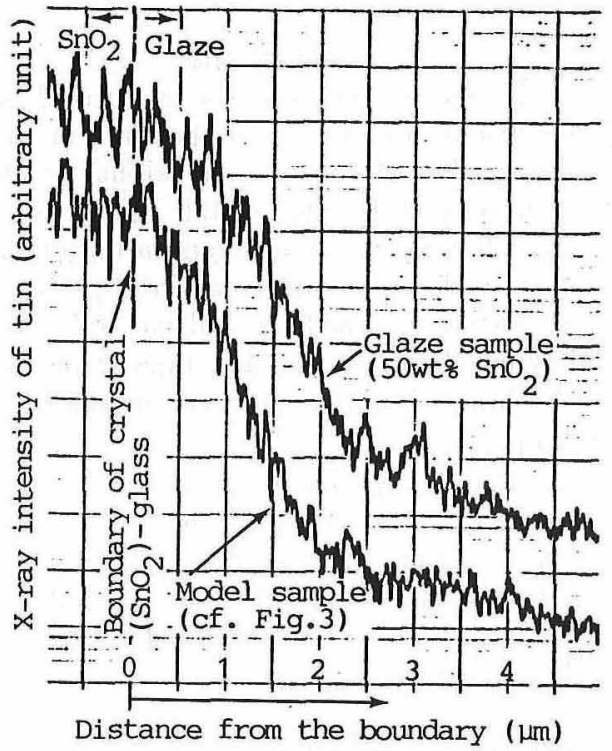

Acc.volt:25KV Sample curr.:0.86nA

Full scale:2kcps Beam diam.:1.5um

Scan. speed: $2 \mu \mathrm{m} / \mathrm{min}$.

Fig. 8. Concentration profile of tin around an undissolved $\mathrm{SnO}_{2}$ particle or substrate of the sample shown in Fig. 3.

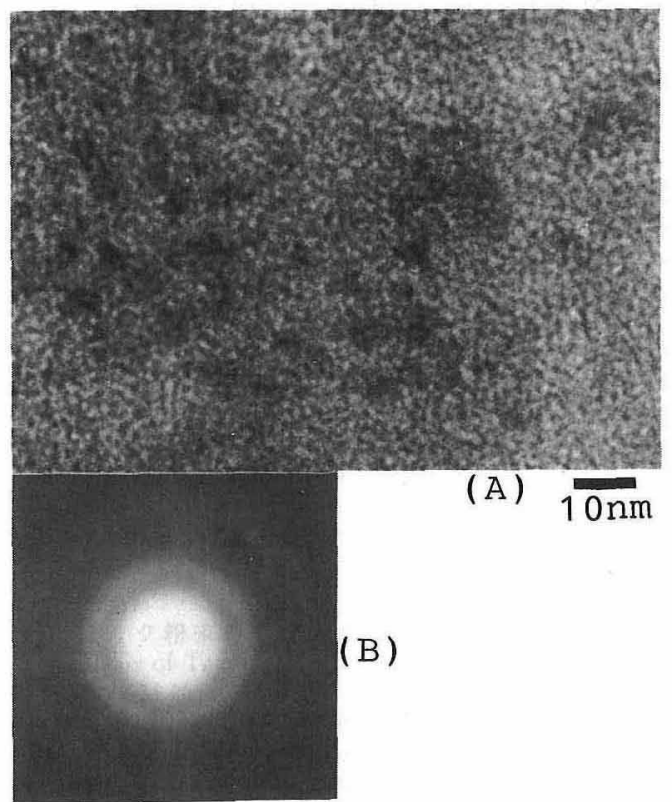

Fig. 9. TEM image observed at high magnification.

(A) The bright field image for the region of low tin concentration ( $1 \mathrm{wt} \% \mathrm{SnO}_{2}$ ),

(B) The electron diffraction pattern for the same region as (A) seemingly crystallized during cooling. The concentration of tin around the large $\mathrm{SnO}_{2}$ particle decreases with the distance from its surface into the glaze as shown in Fig. 8.

The microstructure of Fig. 5 was taken in the region of high tin concentration in solution layer. In the region of low tin concentration $(1 \mathrm{wt} \%$ $\mathrm{SnO}_{2}$ ) in solution layer, only few small crystalline $\mathrm{SnO}_{2}$ particles can be found as shown in Fig. 9 (A) and the electron diffraction pattern shows nearly halo with a few weak rings and spots as shown in Fig. $9(\mathrm{~B})$. In the region of less conductive base glaze where tin could not be detected, no small crystalline $\mathrm{SnO}_{2}$ particle can be found and the electron diffraction pattern shows completely halo as shown in Figs. 10 (A) and $(B)$.

These results again show that small $\mathrm{SnO}_{2}$ particles are responsible to the electrical conduction in the solution layer.

\subsection{Conductivity of the solution layer}

The conductivity of the solution layer was estimated from the conductivities of semiconducting $\mathrm{SnO}_{2}$ crystal and the diffusion couple specimen (see Fig. 3). Figure 11 shows the change of conductivity in solution layer with the distance from the surface of semiconducting $\mathrm{SnO}_{2}$ substrate. The result is compared with that of the previous calculation ${ }^{11}$ obtained with Bube's

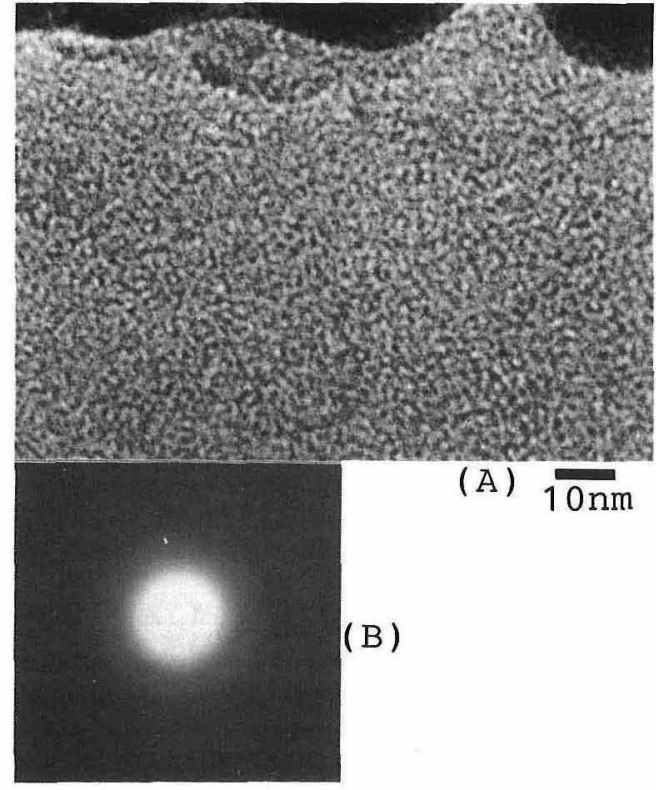

Fig. 10. TEM image observed at high magnification in the base glaze.

(A) The bright field image for the region of extremely low tin concentration,

(B) The electron diffraction pattern corresponding for (A) 


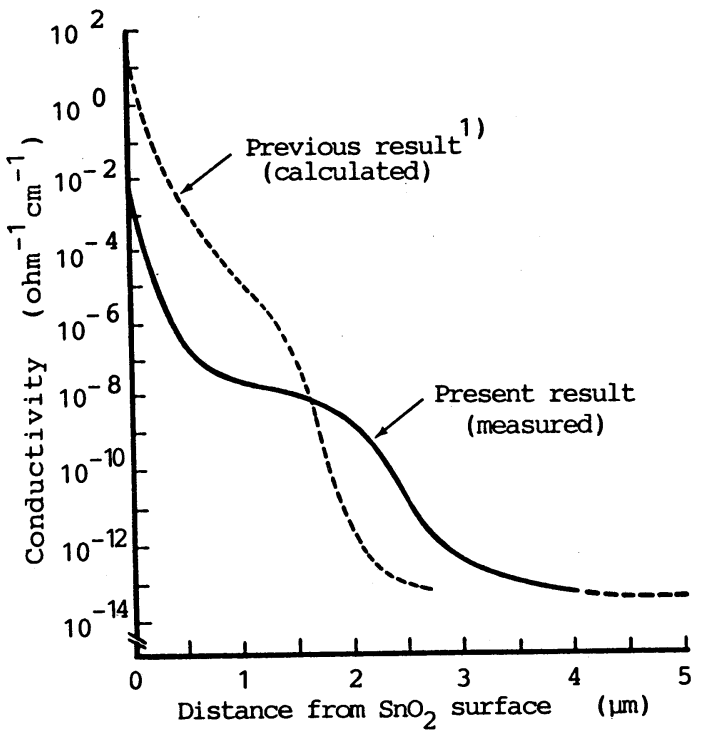

Fig.11. Conductivity profiles in the solution layer determined in the present study and in the previous theoretical approach. ${ }^{1)}$

equation; This equation can be applied to calculate a conductivity of a composite in which inclusions of cubic particles are dispersed in a matrix having different conductivity. Comparison of Fig. 11 with Fig. 8 shows good correlation between the changes of conductivity with distance and tin concentration in the solution layer. Moreover, Fig. 11 shows that the conductivity of the solution layer decreases non-linearly with distance from the surface of semiconducting $\mathrm{SnO}_{2}$ particle. The present result of Fig. 11 agreed semi-quantitatively with the previous calculation. ${ }^{11}$

\section{Conclusions}

(1) It was experimentally confirmed that high electrical conduction of the present glaze was attributed to the three dimensional conduction path formed by the mutal connection of highly conductive solution layers in the vicinity of undissolved semiconducting $\mathrm{SnO}_{2}$ particles.

( 2 ) Extremely small crystalline $\mathrm{SnO}_{2}$ particles having diameter smaller than $8 \mathrm{~nm}$ were found by high resolution electron microscope in the solution layer.

(3) Model experiment using the semiconducting $\mathrm{SnO}_{2}$ and glass diffusion couple showed that the conductivity in the solution layer changed non-linearly with distance from the surface of an undissolved semiconducting $\mathrm{SnO}_{2}$ particle into the matrix region.

Acknowledqments The authors thank Dr. Yoshio Bando of National Institute for Research in Inorganic Materials, Science and Technology Agency for ion-thinning of the sample, and Dr. Chihiro Kaito and Dr. Yoshino Saito of Department of Physics of Kyoto Institute of Technology for the TEM and SEM observations.

\section{Reference}

1) M. Nakamura, H. Shiomi, S. Okuda and T. Nagano, Yogyo-Kyokai-Shi, 93, 170-74 (1985). 